\title{
The effect of the surface modification of carbon nanotubes on their disper- sion in the epoxy matrix
}

\author{
Maria Wladyka-Przybylak ${ }^{1}$, Dorota Wesolek ${ }^{1}$, Weronika Gieparda ${ }^{1}$, Anna Boczkowska ${ }^{2}$, \\ Ewelina Ciecierska ${ }^{2}$
}

${ }^{1}$ Institute of Natural Fibres and Medicinal Plants, Poznań, Poland, e-mail: weronika.gieparda@iwnirz.pl

${ }^{2}$ University of Technology, Faculty of Materials Science and Engineering, Warsaw, Poland

\begin{abstract}
Functionalization of multi-walled carbon nanotubes (MWCNTs) has an effect on the dispersion of MWCNT in the epoxy matrix. Samples based on two kinds of epoxy resin and different weight percentage of MWCNTs (functionalized and non-functionalized) were prepared. Epoxy/carbon nanotubes composites were prepared by different mixing methods (ultrasounds and a combination of ultrasounds and mechanical mixing). CNTs modified with different functional groups were investigated. Surfactants were used to lower the surface tension of the liquid, which enabled easier spreading and reducing the interfacial tension. Solvents were also used to reduce the liquid viscosity. Some of them facilitate homogeneous dispersion of nanotubes in the resin. The properties of epoxy/nanotubes composites strongly depend on a uniform distribution of carbon nanotubes in the epoxy matrix. The type of epoxy resin, solvent, surfactant and mixing method for homogeneous dispersion of CNTs in the epoxy matrix was evaluated. The effect of CNTs functionalization type on their dispersion in the epoxy resins was evaluated on the basis of viscosity and microstructure studies.
\end{abstract}

\section{INTRODUCTION}

The discovery of multi-walled carbon nanotubes (MWCNTs) ${ }^{1,2}$ and single-walled carbon nanotubes (SWCNTs) ${ }^{3,4}$ has generated new perspectives in many fields of science and technology ${ }^{5,6}$. Carbon nanotubes (CNTs) are increasingly attracting scientific and industrial interest due to their outstanding characteristics. The CNT walls resemble rolled-up graphite-like sheets with strong covalent $\mathrm{sp}^{2}$ bonds. In accordance with their graphitic structure, CNTs are characterized by high thermal conductivity and electrical conductivity that can be either of a semi-conductor or metal type. The Young's modulus of carbon nanotubes can be as high as $1000 \mathrm{GPa}$, which is approximately five times higher than that of steel. The tensile strength of carbon nanotubes can be up to 150 $\mathrm{GPa}$, about 40 times higher than that of stee $\mathbf{l}^{6-10}$. The combination of the previously mentioned material properties together with the aspect ratio in the range of several thousands, makes CNTs promising candidates for the reinforcement for polymer composites. However, the high specific surface area results in a strong tendency to agglomeration. Nanoropes (agglomerates) are difficult to separate and infiltrate with the matrix ${ }^{11}$.

Epoxy resins (EP) have been widely used in practical applications, e.g. as adhesives ${ }^{12}$, construction materials ${ }^{13}$, composites $^{14}$, laminates ${ }^{15}$ and coatings ${ }^{16}$ owing to their excellent mechanical properties, low cost, ease of processing, good adhesion to many substrates, and good chemical resistance. As most polymers, epoxy resins are electrical insulators. Air frictions can damage the materials because of an accumulation of charges. The preparation of composites with conductive fillers allows solving this problem for a sufficient rate of charge in the matrix. In most of the publications, low-viscosity epoxy resins obtained from Bisphenol $\mathrm{A}^{17-21}$ and also Bisphenol $\mathrm{F}^{22,23}$ were used.

The essential problem in forming CNT/epoxy resin composites is homogeneous dispersion of nanotubes in the polymer matrix. There are three different techniques mentioned in the literature: mechanical mixing ${ }^{24,25}$, ultrasonic action ${ }^{20,26}$ and calendering ${ }^{11,27}$. The last technology was pointed out as the most effective ${ }^{17}$. The second problem is a strong interfacial bonding between the CNTs and the polymer matrix. Measurement of the rheological property is useful to examine the changes in dispersion state and interfacial bonding affected by surface modification. There are a few reports on rheological behaviour of CNT/ polymer composites. Pötschke et al. ${ }^{28}$ investigated the rheological properties of the CNT/polycarbonate composites. It was found that the increase in the viscosity of the composites filled with CNTs was higher than that of polymer composites filled with carbon fibres or carbon blacks. Mitchell et al. ${ }^{29}$ examined the linear viscoelastic properties of the composites prepared with pristine single walled carbon nanotubes (SWNTs) and organically modified SWNTs in a polystyrene matrix. It was found that the composites filled with functionalized CNTs had better dispersion and showed higher storage modulus and dynamic shear viscosity at low frequency. Kim et al. ${ }^{30}$ reported that the CNTs modified by acid treatment, plasma oxidation and amine treatment were well dispersed in the epoxy matrix and had strong interfacial bonding with the polymer matrix. The nanocomposite containing the modified CNTs exhibited higher storage and loss moduli and shear viscosity than those with the untreated CNTs, because the surface treatments provided more homogeneous dispersion of CNTs and stronger interaction between the CNT and the polymer matrix. Gojny et al. ${ }^{31}$ showed that the functionalisation of CNTs led to reduced agglomeration and provided evidence for an improved interaction between the nanotubes and the epoxy resin.

Previously, the authors conducted studies on the improvement of the electrical conductivity of epoxy matrix composites without deterioration of mechanical properties. Carbon nanotubes have proven to be a good additive to improve the electrical conductivity in epoxy resin.

Properties of MWCNTs/epoxy composites depend on the homogeneous dispersion of carbon nanotubes in the epoxy resin. Uniform dispersion is prerequisite to improve the properties of the composites. Then, the quality of the dispersion depends partially on the type of carbon 
nanotubes modification. In this paper, in order to evaluate the nanotubes distribution in the epoxy resins, viscosity and microstructure tests were performed.

\section{EXPERIMENTAL}

\section{Materials}

Characterization of materials used in our studies is described in Table 1. Three kinds of multi-walled carbon nanotubes supplied by two companies were used - nonfunctionalized and modified by different groups. Two types of epoxy resins were tested. A hardener has a long pot life, which is useful during the vaporization process. Two kinds of surfactants (viscosity depressants and air release additives) and four solvents to reduce the viscosity in the initial step of mixing were used.

\section{Methods}

The preparation of mixtures was performed using a VCX 750 Watt Ultrasonic Processor and a IKA EUROSTAR power control-visc mechanical stirrer. An ultrasonic processor was equipped with temperature con- trol. A solid tip (19 $\mathrm{mm}$ in diameter) was connected to the converter. The tip was inserted directly in the resin to obtain better dispersion. Intensive interactions between the mixture and the tip were observed during sonication. The amplitude was equal to $40-60 \%$ and frequency to 20 $\mathrm{kHz}$.

Viscosity tests were performed using a Brookfield viscosimeter with a spindle No. 87. The samples were placed in a Medingen B2/E5 thermostat.

Observations of the microstructure were carried out using the High Resolution Scanning Electron Microscope (HRSEM) LEO 1530 (Zeiss) and HITACHI S-5500, Atomic Force Microscope (AFM) - Scanning Probe Microscope Multi Mode AFM Nanoscope with IIIA controller (DI). The samples were prepared using a rotary microtome LEICA RM2165 and ultramicrotome (Leica EM UC 6).

\section{Sample preparation}

All nanotubes were dried in a vacuum oven before performing any further process. Drying in the vacuum oven was performed in order to remove the adsorbed water before adding nanotubes to a resin or solvent. Two

Table 1. Materials used in the study

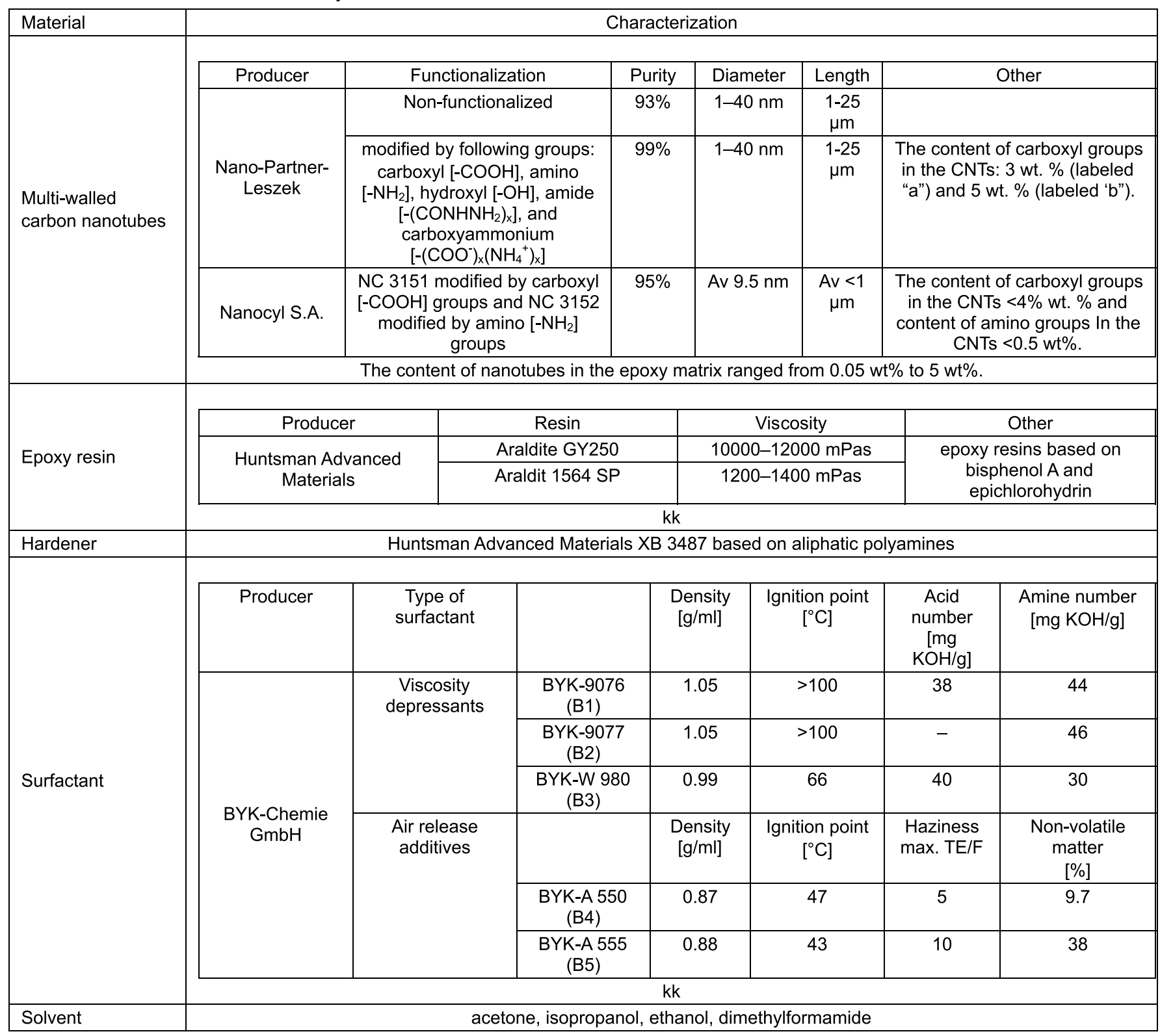


ways were used to prepare the epoxy/MWCNTs composites:

- Ultrasound method: Carbon nanotubes, dried to a constant weight, were broken in the solvent by the ultrasonicator. Then the resin was added to the mixture and the ultrasonication process was continued. Next, the solvent was evaporated by using a water aspirator and the ultrasonication process was continued. This was followed by the addition of a curing agent, the samples were degassed in the vacuum oven, cast to silicone moulds and cured at $60^{\circ} \mathrm{C}$ for $4 \mathrm{~h}$ and at $120^{\circ} \mathrm{C}$ for $4 \mathrm{~h}$.

- Combination of ultrasound and mechanical mixing method: The nanotubes dried to a constant weight, were introduced into the resin previously heated and were mixed by a mechanical stirrer. Then the samples were sonicated. Next, the curing agent was added, the samples were degassed in a vacuum oven, cast to silicone moulds and cured at $60^{\circ} \mathrm{C}$ for $4 \mathrm{~h}$ and at $120^{\circ} \mathrm{C}$ for $4 \mathrm{~h}$.

\section{RESULTS AND DISCUSSION}

The influence of different kinds of surfactant on the resin viscosity are shown in the Table 2:

Degassing time was determined by placing approximately $25 \mathrm{~g}$ of resin in a beaker followed by mixing with $1 \mathrm{wt} \%$ of surfactants. The beakers were transferred to a vacuum oven at $40^{\circ} \mathrm{C}$. Experiments with high-viscosity resin with all surfactants (B1 to B5) showed that BYK-A 550 (B4) lowered the resin viscosity to the highest extent and facilitated release of air in the shortest time. Since the best results were obtained for the surfactant B4, only this surfactant was used in further studies. The surfactant concentration was lowered to $0.1 \mathrm{wt} \%$ in order to avoid deterioration in the mechanical properties of the resin. The release of air was satisfactory at the above concentration. The viscosity of low-viscosity resin was lowered slightly. The results are shown in Fig. 1.

The tests on the solvent effect on the nanotubes dispersion were performed. In the case of isopropanol, it was difficult to obtain a uniform mixture with the resin. The

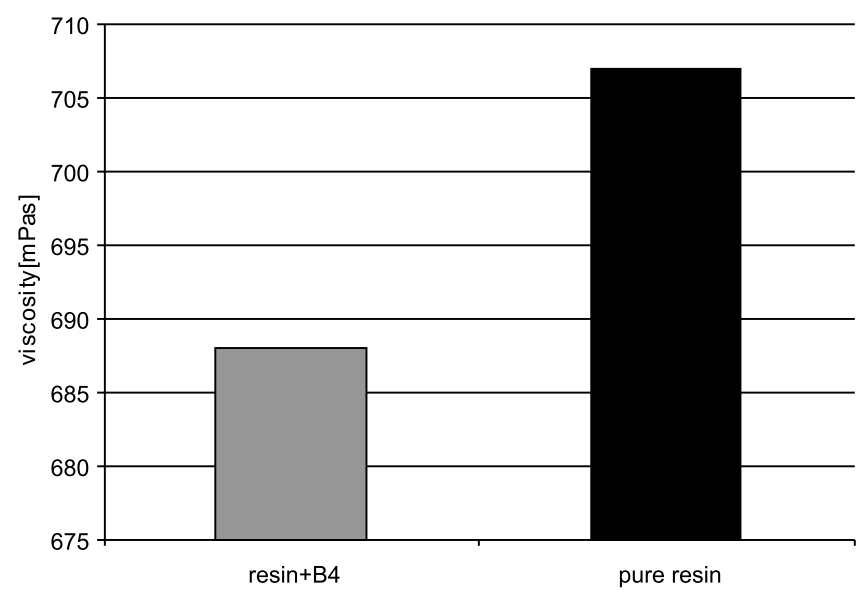

Figure 1. Viscosity of the low-viscosity resin after the addition of surfactant B4 evaporation of dimethylformamide was difficult because of its high boiling point. Acetone and ethanol appeared to be better; there were no problems with evaporation and the dispersion of nanotubes was good (agglomerates were not visible). It was decided to use only ethanol in further experiments because of a little better dispersion of nanotubes while using this solvent.

After the choices of surfactant and solvent, tests for the selection of resin were performed.

Firstly, pure epoxy resins were tested for their viscosity. Araldite GY 250 has a relatively high viscosity at room temperature (10000-12000 mPas) and the viscosity decreases approximately by a factor of two for every $5^{\circ} \mathrm{C}$ increase in temperature. The second epoxy resin, Araldit LY 1564 SP has much lower viscosity $\left(\eta_{25}=1000-1200\right.$ $\mathrm{mPas}$ ). Lower viscosity facilitates the degassing process and results in better mechanical properties. Studies on the influence of the ultrasonication process on the pure resin viscosity showed that there are no changes of the resin viscosity after this process. It was also found that ultrasonication has no effect on resin microstructure and mechanical properties.

Next, the samples containing nanotubes in high-viscosity resin and the samples with low-viscosity resin were prepared and their viscosity was measured. In the case of high-viscosity resin (Table 3), viscosity measurements took more time and the viscosity was more correlated with the rotation speed than in the case of the samples with lowviscosity resin (Table 4). The viscosity of the samples ranged from 4757 to $7353 \mathrm{mPas}$ for the composites with modified nanotubes purchased from the Polish company and high-viscosity resin. The viscosity of the samples based on low-viscosity resin and the same type of nanotubes was significantly lower and independent of the type of carbon nanotubes $\left(\eta_{30}=1080-1258 \mathrm{mPas}\right)$ for all the samples of low-viscosity resin and modified nanotubes from NanoPartner-Leszek. Samples with low viscosity resin were easier for degassing and casting to the moulds. The same tendency was observed in the case of the samples with non-modified nanotubes and modified nanotubes from Nanocyl. A low-viscosity resin Araldit LY 1564 SP was selected for further studies.

Comparison of all types of carbon nanotubes used in our study led to the conclusion that in all types of the samples the dispersion of the modified carbon nanotubes was worse than that of the unmodified ones. This is the result of the strong tendency of modified nanotubes to agglomerate with regard to interactions of their functional groups. However, significant differences in the viscosity and associated dispersion were observed depending on the nanotubes producer. The viscosity of the samples containing nanotubes from Nanocyl differed from that of the samples containing nanotubes from Nano-Partner-Leszek (Fig. 2). The samples with $0.05 \mathrm{wt} \%$ of nanotubes from the Belgian company have viscosity similar to that of the samples with the ten times higher content of modified nanotubes of Polish origin. The viscosity of the samples with aminated nanotubes from Nanocyl increases with a

Table 2. Degassing time and viscosity of high-viscosity resin with different surfactants

\begin{tabular}{|c|r|r|r|r|r|}
\hline & B4 & B5 & B3 & B2 \\
\hline degassing time $[\mathrm{h}]$ & 1 & 1 & 2 & 3.5 \\
\hline viscosity [mPas] at $30^{\circ} \mathrm{C}$ & 3335 & 3942 & 4056 & 3.5 & 4965 \\
\hline
\end{tabular}


Table 3. Viscosity of samples with high-viscosity resin and functionalized nanotubes from Nano-Partner-Leszek depending on the rotation speed at $30^{\circ} \mathrm{C}[\mathrm{mPas}]$

\begin{tabular}{|l|c|c|c|c|}
\hline \multirow{2}{*}{ Samples with 0.5 wt. \% of CNTs } & \multicolumn{3}{c|}{ Viscosity } & \multirow{2}{*}{ Difference depending on rpm } \\
\cline { 2 - 4 } & 0.3 & 0.6 & 1.5 & \multirow{2}{*}{171} \\
\hline composite with carboxylated (a) CNTs and a surfactant & 5648 & 5477 & 5549 & 330 \\
\hline composite with carboxylated (b) CNTs & 5900 & 5709 & 5570 & 38 \\
\hline composite with carboxylated (b) CNTs and a surfactant & 5193 & 5155 & 5162 & 102 \\
\hline composite with aminated CNTs & 4852 & 4757 & 4859 & 121 \\
\hline composite with aminated CNTs and a surfactant & 5344 & 5231 & 5352 & 644 \\
\hline composite with hydroxylated CNTs & 7353 & 6823 & 6709 & 227 \\
\hline composite with hydroxylated CNTs and a surfactant & 5913 & 5686 & 5746 & 247 \\
\hline pure epoxy resin & 4814 & 4567 & 4746 & \\
\hline
\end{tabular}

Table 4. Viscosity of samples with low-viscosity resin and functionalized nanotubes from Nano-Partner-Leszek depending on the rotation speed at $30^{\circ} \mathrm{C}[\mathrm{mPas}]$

\begin{tabular}{|l|c|c|c|c|}
\hline \multirow{2}{*}{ Samples with 0.5 wt. \% of CNTs } & \multicolumn{2}{|c|}{ Viscosity } & \multirow{2}{*}{ Difference depending on rpm } \\
\cline { 3 - 5 } & 1.5 & 3 & 6 & 62 \\
\hline composite with carboxylated (a) CNTs & 1258 & 1235 & 1196 & 19 \\
\hline composite with carboxylated (a) CNTs and a surfactant & 1175 & 1171 & 1190 & 19 \\
\hline composite with carboxylated (b) CNTs & 1205 & 1186 & 1190 & 12 \\
\hline composite with carboxylated (b) CNTs and a surfactant & 1107 & 1095 & 1097 & 4 \\
\hline composite with aminated CNTs & 1122 & 1118 & 1120 & 10 \\
\hline composite with aminated CNTs and a surfactant & 1122 & 1114 & 1112 & 9 \\
\hline composite with hydroxylated CNTs & 1129 & 1122 & 1131 & 49 \\
\hline composite with hydroxylated CNTs and a surfactant & 1129 & 1080 & 1084 & 1.8 \\
\hline pure epoxy resin & - & 708.8 & 707 & \\
\hline
\end{tabular}

rise in the content of nanotubes, similarly to the viscosity of samples with non-functionalized nanotubes, whereas the viscosity of the samples with modified nanotubes from Nano-Partner-Leszek remained at the same level, irrespective of the nanotubes content.

The type, size and purity of CNT (different for each producer) is also very important for the comparison of the viscosity of samples depending on a functional group. None of the modified nanotubes supplied by Nano-Partner-Leszek gave uniform dispersion. After the initial mixing with a solvent, a large number of big aggregates were visible. However, when ultrasonication was performed, most of them broke, but dispersion remained unsatisfactory. The largest agglomerates were found in the case of the sample containing hydroxylated nanotubes. In the case of the Nanocyl nanotubes the dispersion was homogeneous. Significant differences were observed depending on a functional group. The samples with aminated nanotubes had higher viscosity than the samples with carboxylated nanotubes (slightly higher for lower nanotube contents, and significantly higher for the highest nanotube content).

The use of surfactant in the sample with aminated nanotubes from Nanocyl slightly increased the viscosity $\left(\eta_{30}=3448 \mathrm{mPas}\right.$ for sample with $0.5 \mathrm{wt} \%$ of CNTs without a surfactant compared to $\eta_{30}=4186 \mathrm{mPas}$ for the

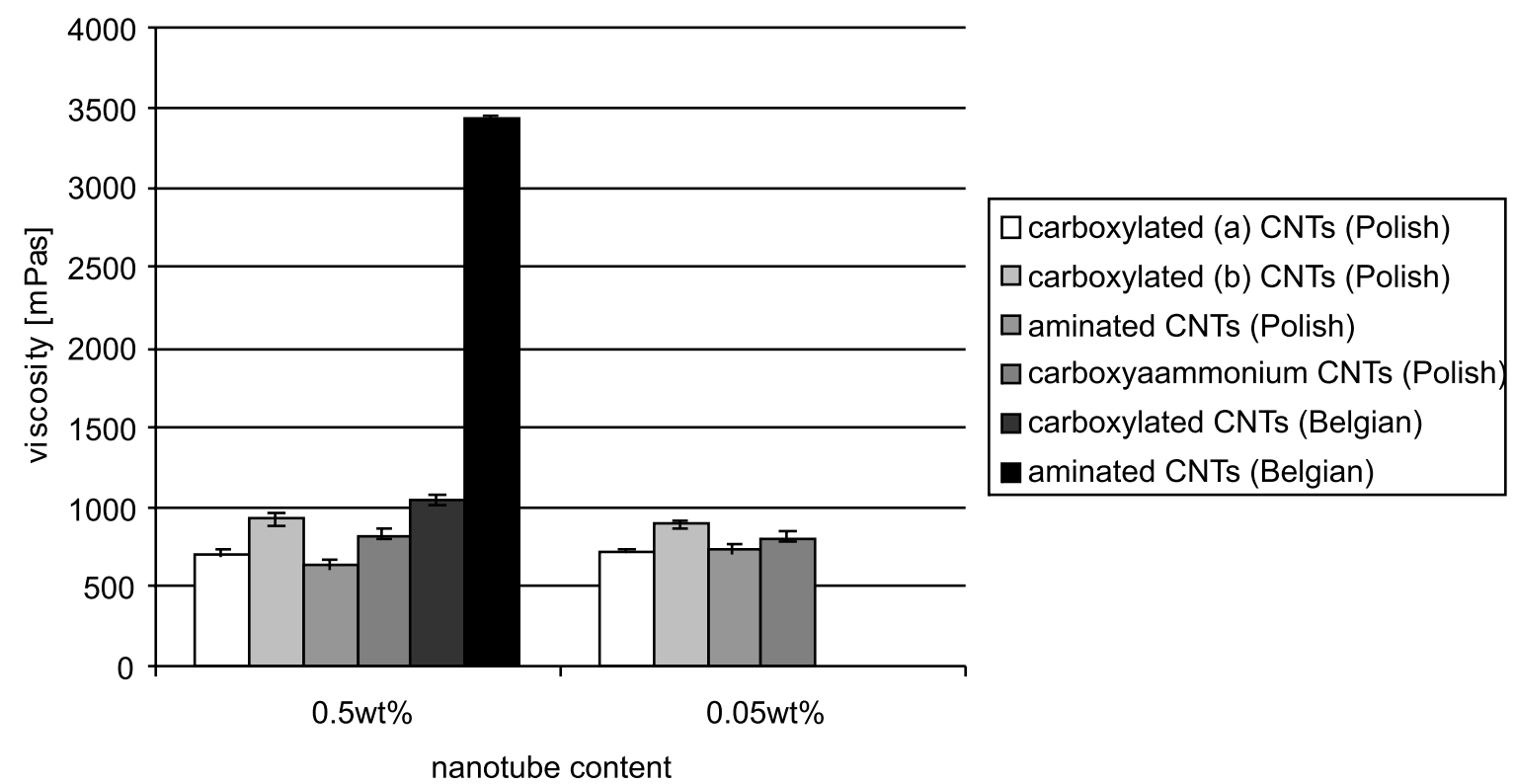

Figure 2. Comparison of viscosity of samples with low-viscosity resin and selected carbon nanotubes prepared by ultrasound method 


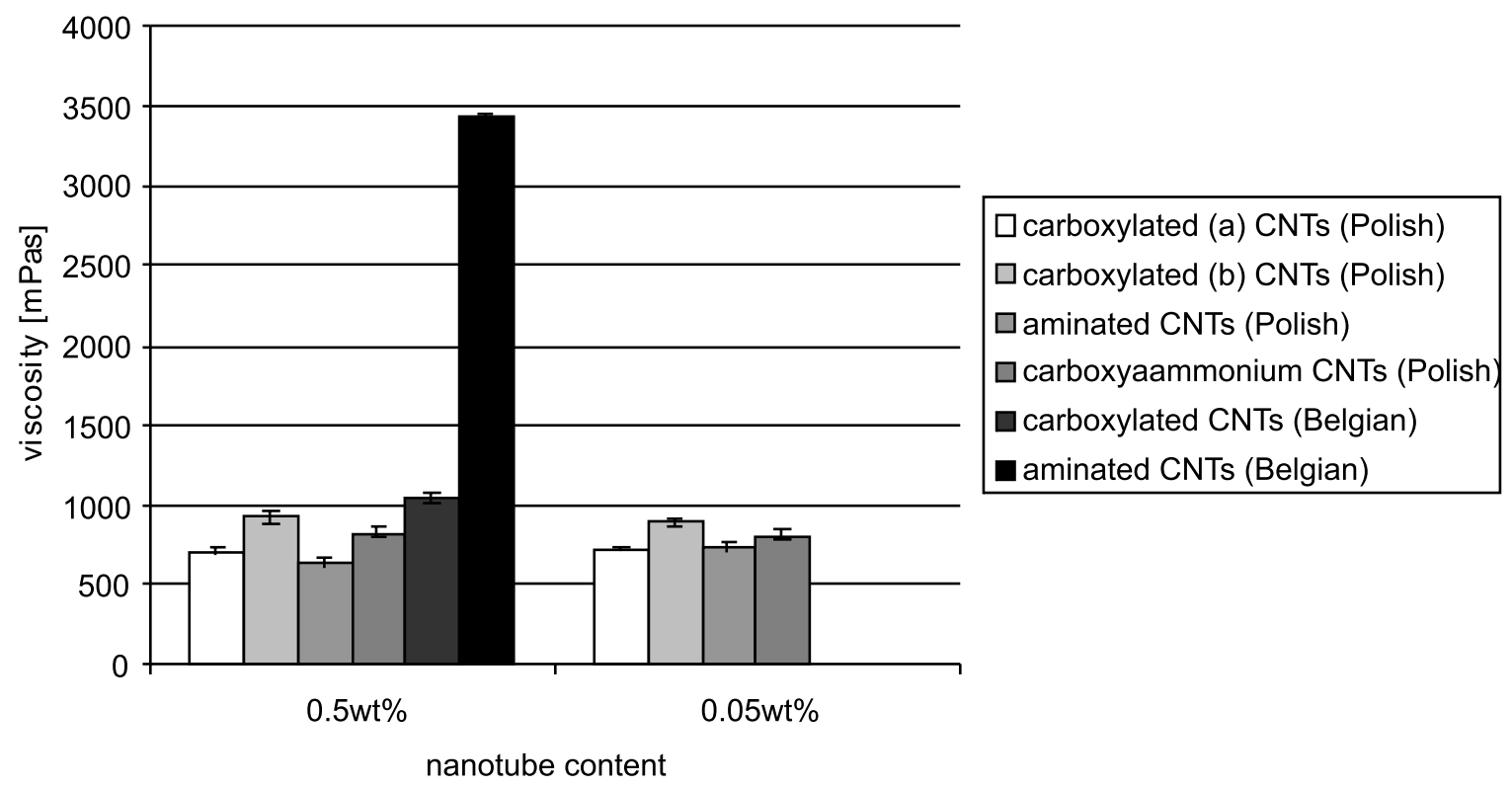

Figure 3. Dependence of viscosity on the type of functionalization group in nanotubes prepared by combination of ultrasound and mechanical mixing
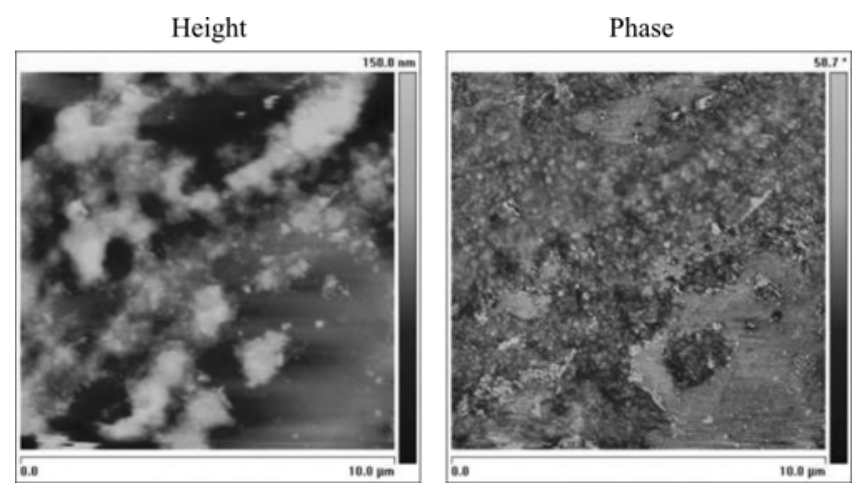

Figure 4. AFM images of epoxy/nanotube composite with $0.5 \mathrm{wt} \%$ of unmodified nanotubes

sample with the same amount of nanotubes with a surfactant) and the dispersion is better for this sample, which was confirmed by SEM observation. The dispersion in the sample with aminated nanotubes from Nanocyl with a surfactant was the best (Fig. 7). Figure 2 shows the results of viscosity measurements for the selected samples prepared in the ultrasound method.

Figure 3 shows the differences of the viscosity of the samples with a different content of the modified nanotubes in the epoxy resin prepared according to the combination method of mechanical mixing and ultrasound. The differences between nanotubes are visible. The dispersion of modified nanotubes from Nano-Partner-Leszek depends on the nanotube type. The highest viscosity and dispersion was found for the sample with carboxylated (b) nanotubes (functional groups content in the nanotubes is $5 \mathrm{wt} \%$, nanotube content in a resin is $0.5 \mathrm{wt} \%, \eta_{30}=924 \mathrm{mPas}$ ), but it was much worse than that of the modified nanotubes from Nanocyl $\left(\eta_{30}=3434 \mathrm{mPas} ; 0.5 \mathrm{wt} \%\right.$ of aminated CNTs and $\eta_{30}=1044 \mathrm{mPas} ; 0.5 \mathrm{wt} \%$ of carboxylated CNTs).

For accurate determination of the dispersion, microstructure observation was performed; the observations helped to adjust mixing techniques and parameters. It was found that by using the ultrasound method, it was possible to obtain a uniform distribution of unmodified CNTs in the epoxy matrix. The AFM images of epoxy/nanotube composite with unmodified nanotubes are shown in Fig. 4.
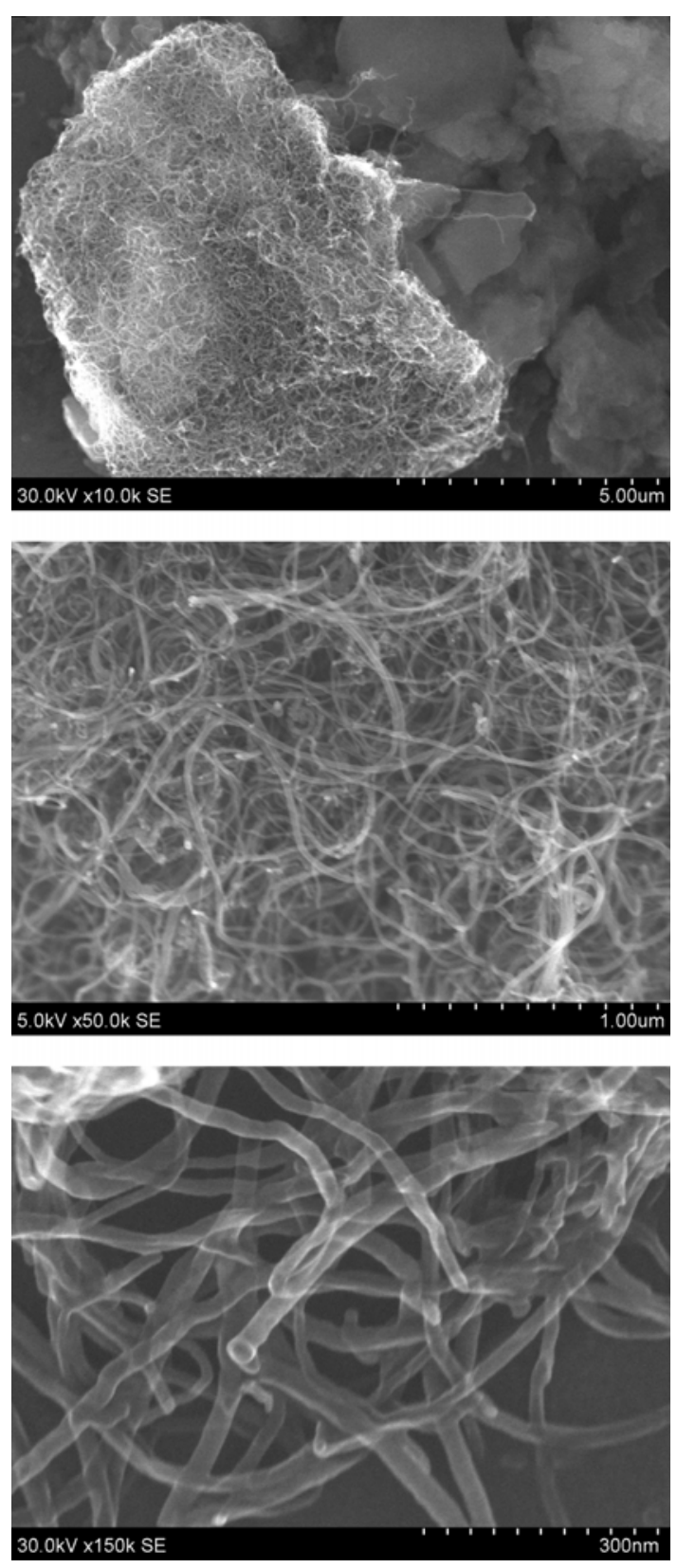

Figure 5. SEM images of non-functionalized MWCNTs 

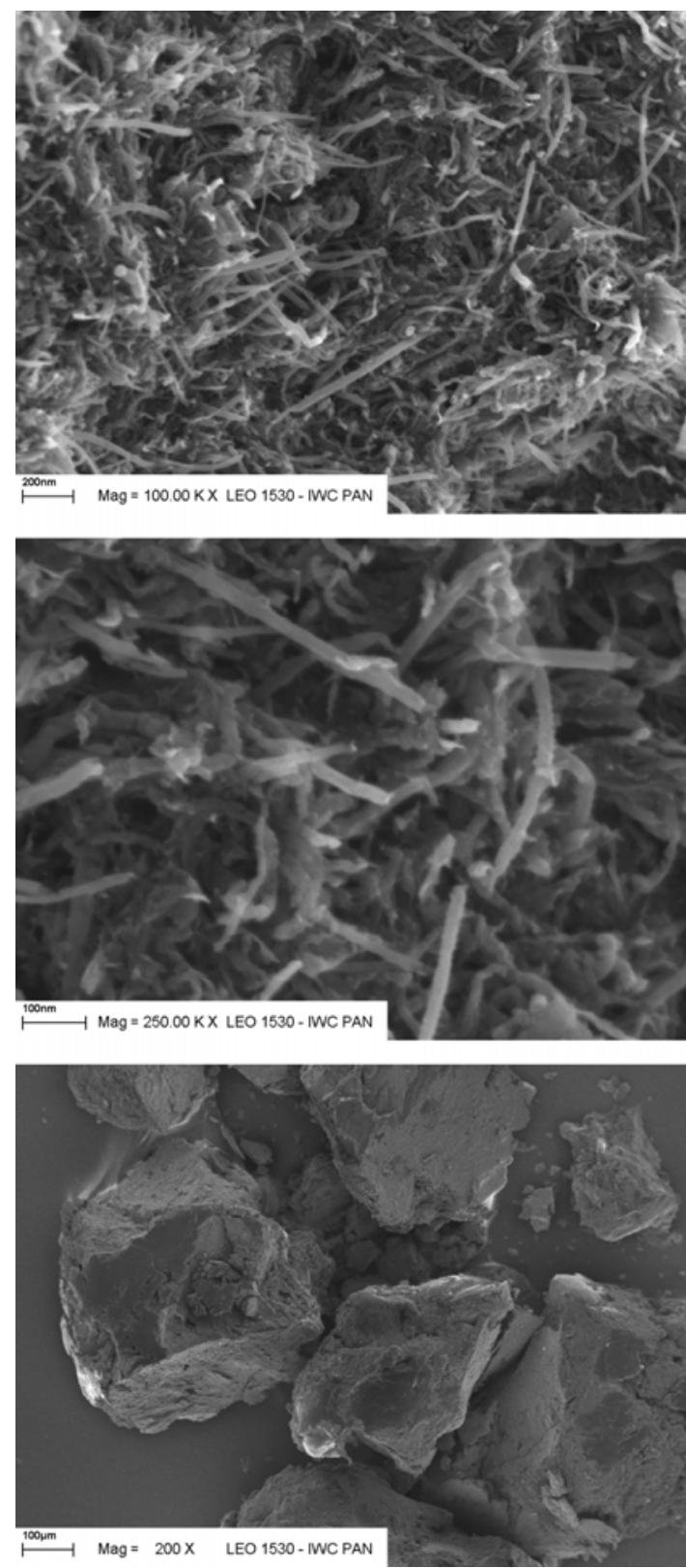

Figure 6. SEM images of MWCNTs functionalized with -OH groups, supplied by the Polish company

In this case the dispersion was good and big agglomerates were not found. Some single nanotubes dispersed in the epoxy matrix were observed.

Modified nanotubes from Polish company form bigger agglomerates than unmodified ones (Figs. 5, 6).

Achievement of an uniform dispersion of carbon nanotubes in the epoxy matrix was impossible, many big agglomerates were observed and it was difficult to crash them in the epoxy matrix. None of the mixing techniques or parameters, addition of surfactants or different solvents gave satisfactory results. The addition of $5 \mathrm{wt} \%$ of modified nanotubes appeared to be unsuccessful, too. SEM images of epoxy/nanotube composite with $5 \mathrm{wt} \%$ of nanotubes modified with $\left(\mathrm{COO}^{-}\right)_{\mathrm{x}}\left(\mathrm{NH}_{4}{ }^{+}\right)_{\mathrm{x}}$ groups are presented in Fig. 7 as an illustration.

Modified nanotubes supplied by Nanocyl were more susceptible to uniform dispersion in the epoxy matrix. SEM (Fig. 8) and AFM (Fig. 9) images show epoxy/ nanotube composite with $0.5 \mathrm{wt} \%$ of nanotubes modified
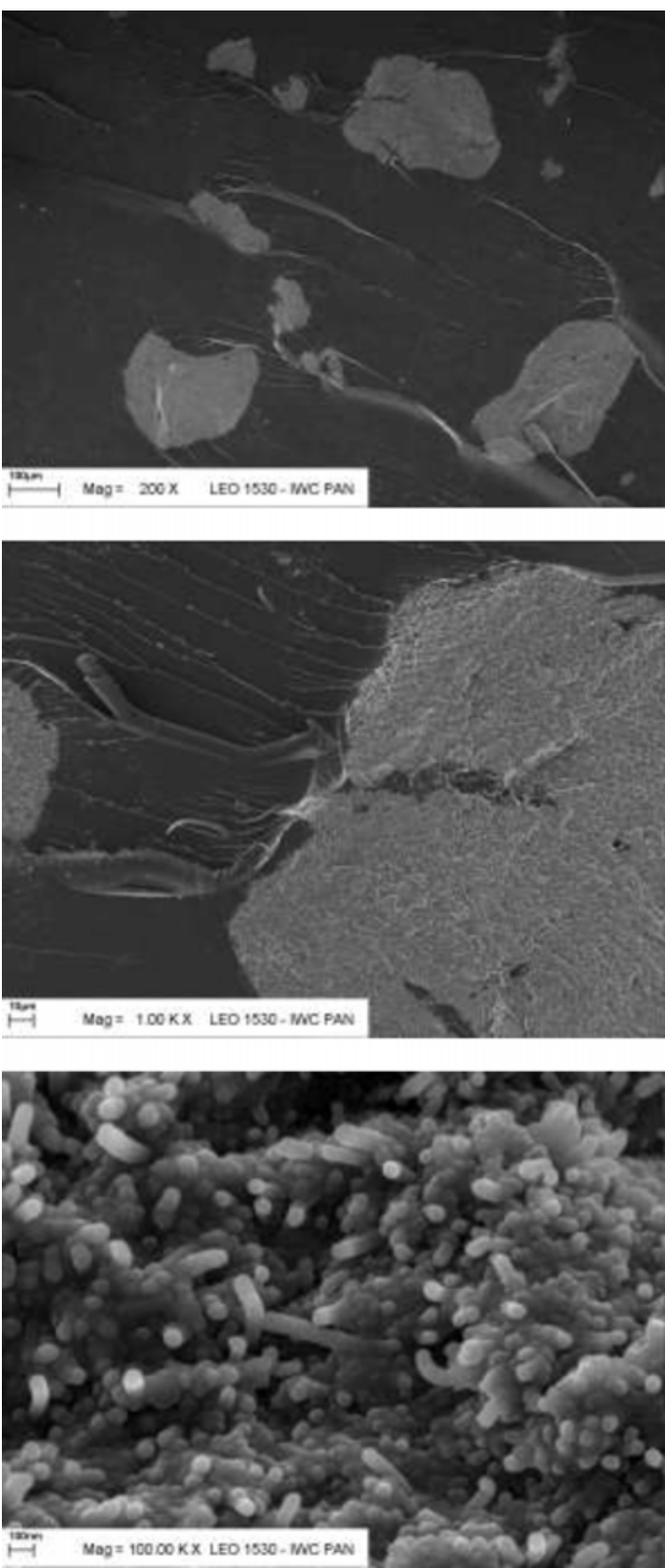

Figure 7. SEM images of epoxy/nanotube composite with $5 \mathrm{wt} \%$ of nanotubes modified with $\left(\mathrm{COO}^{-}\right)_{\mathrm{x}}\left(\mathrm{NH}_{4}{ }^{+}\right)_{\mathrm{x}}$ groups supplied by the Polish company

with $-\mathrm{NH}_{2}$ groups with a surfactant prepared by ultrasound method.

\section{CONCLUSIONS}

1. The best dispersion of the nanotubes in the epoxy resins was obtained using:

a. low-viscosity epoxy resin;

b. ethanol in the initial step of mixing;

c. surfactant BYK-A 550;

d. two mixing methods - ultrasonic mixing or combination of ultrasound and mechanical mixing;

2. Very good dispersion is exhibited by modified nanotubes from Nanocyl and is dependent on the nanotubes type (functional groups) and the best for aminated nanotubes.

3. Good dispersion was obtained in composites with non-modified nanotubes prepared in the ultrasound method. 

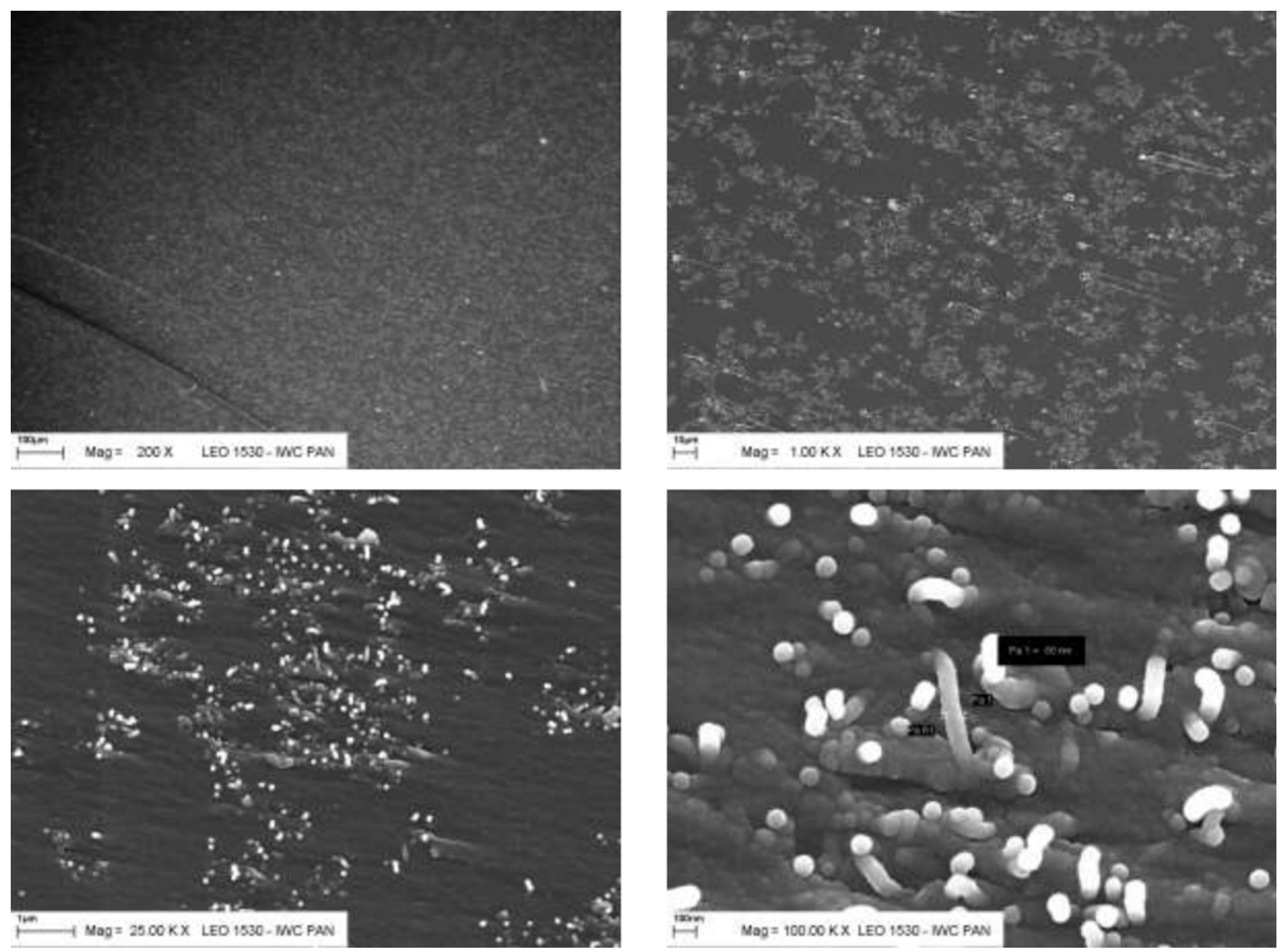

Figure 8. SEM images of epoxy/nanotube composite with $0.5 \mathrm{wt} \%$ of nanotubes modified with $-\mathrm{NH}_{2}$ groups, supplied by
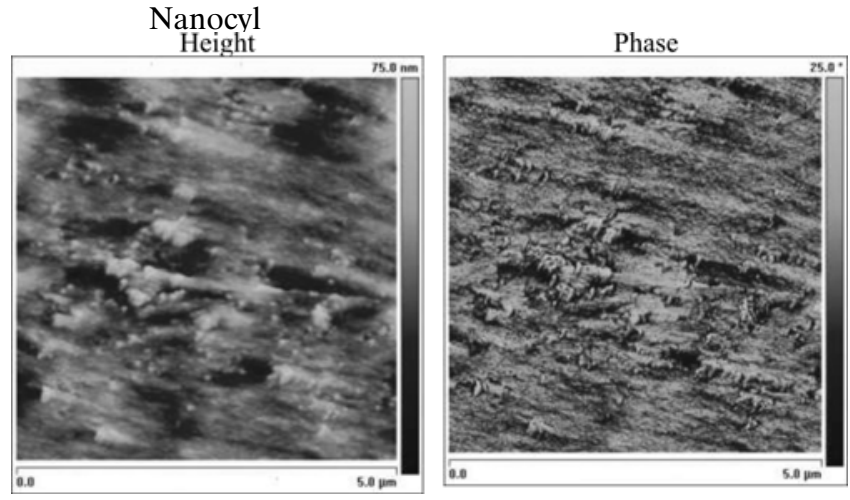

Figure 9. AFM images of epoxy/nanotubes composite with $0.5 \mathrm{wt} \%$ of nanotubes modified with $-\mathrm{NH}_{2}$ groups with a surfactant, supplied by Nanocyl

4. It was not possible to obtain satisfactory dispersion of the modified nanotubes from Nano-Partner-Leszek regardless of the method and the worst dispersion was obtained for hydroxylated nanotubes.

\section{LITERATURE CITED}

1. Iijima, S. (1991). Helical microtubules of graphitic carbon. Nature 354, 56-58. doi:10.1038/354056a0.

2. Nesterenko, A.M., Kolesnik, N.F., Akhmatov, Y.S., Sukhomlin, V.I. \& Prilutski, O.V. (1982). Metals 3 UDK 869.173.23, News of the Academy of Science, USSR, 12-16.
3. Iijima, S. \& Ichihashi, T. (1993). Single-shell carbon nanotubes of 1-nm diameter. Nature 363, 603-605. doi:10.1038/363603a0.

4. Bethune, D.S., Kiang, C.H., Devries, M.S., Gorman, G., Savoy, R. \& Vazquez, J. et al. (1993). Cobalt-catalysed growth of carbon nanotubes with single-atomic-layer walls. Nature 363, 605-607. doi:10.1038/363605a0.

5. Ajayan, P.M. \& Iijima, S. (1993). Capillarity-induced filling of carbon nanotubes. Nature 361, 333-334. doi:10.1038/361333a0.

6. Thostenson, E.T., Ren, Z.F., Chou, T.-W. (2001). Advances in the science and technology of carbon nanotubes and their composites: a review. Compos. Sci. Technol. 61(13), 1899-1912. doi:10.1016/S02663538(01)00094-X.

7. Wildoer, J.W.G., Venema, L.C., Rinzler, A.G., Smalley, R.E. \& Dekker, C. (1998). Electronic structure of atomically resolved carbon nanotubes. Nature 391, 59 62. doi:10.1038/34139.

8. Hone, J., Batlogg, B., Benes, Z., Johnson, A.T. \& Fischer, J.E. (2000). Quantized Phonon Spectrum of Single-Wall Carbon Nanotubes. Science 289, 1730. doi: 10.1126/science.289.5485.1730.

9. Ruoff, R.S. \& Lorents, D.C. (1995). Mechanical and thermal properties of carbon nanotubes. Carbon 33(7), 925-930. doi:10.1016/0008-6223(95)00021-5.

10. Treacy, M.M.J., Ebbesen, T.W. \& Gibson, J.M. (1996). Exceptionally high Young's modulus observed for 
individual carbon nanotubes. Nature 381, 678-680. doi: $10.1038 / 381678 \mathrm{a} 0$

11. Gojny, F.H., Wichmann, M.H.G., Fiedler, B. \& Schulte, K. (2005). Influence of different carbon nanotubes on the mechanical properties of epoxy matrix composites - A comparative study. Compos. Sci. Technol. 65(15-16), 2300-2313. doi:10.1016/j.compscitech.2005.04.021

12. Prolongo, S.G., Rosario, G. \& Urena A. (2006). Comparative study on the adhesive properties of different epoxy resins. Int J Adhesion and Adhesives 26(3), 125132. doi:10.1016/j.ijadhadh.2005.02.004.

13. Neffgen, B. (1985). Epoxy resins in the building industry - 25 years of experience. Int J Cement Comp and Lightweight Concrete 7(4), 253-260. doi:10.1016/02625075(85)90046-6.

14. Toldy, A., Szolnoki, B. \& Marosi, G. (2010) Flame retardancy of fibre-reinforced epoxy resin composites for aerospace applications. Polymer Degradation and Stability Article in Press. doi:10.1016/j.polymdegradstab. 2010.03.021.

15. Kagathara, V.M. \& Parsania, P.H. (2001) Preparation and evaluation of mechano-electrical properties and chemical resistance of epoxy laminates of halogenated bisphenol-C resins. Polymer Testing 20(6), 713-716. doi:10.1016/S0142-9418(00)00071-4.

16. Atta, A.M., Abdou, M.I., Elsayed, A. \& Raga M.E. (2008). New bisphenol novolac epoxy resins for marine primer steel coating applications. Progress in Organic Coatings 63(4), 372-376. doi:10.1016/j.porgcoat. 2008.06.013.

17. Kovacs, J.Z., Andersen, K., Puls, J.R., Pardo Garcia, K., Schossig, M., Schulte, K. \& Bauhofer, W. (2007). Analyzing the quality of carbon nanotube dispersions in polymers using scanning electron microscopy. Carbon 45(6), 1279-1288. doi:10.1016/j.carbon.2007.01.012.

18. Abdalla, M., Detrick, D., Adibempe, D., Nyairo, E., Robinson, P. \& Thompson, G. (2007). The effect of interfacial chemistry on molecular mobility and morphology of multiwalled carbon nanotubes epoxy nanocomposite. Polymer 48(19), 5662-5670. doi:10.1016/j.polymer. 2007.06.073.

19. Young, R.J. \& Lucas, M. (2007). Effect of residual stresses upon the Raman radial breathing modes of nanotubes in epoxy composites. Compos. Sci. Technol. 67(5), 840-843. doi:10.1016/j.compscitech.2005.12.031

20. Jianfeng, S., Weishi, H., Liping, W., Yizhe, H. \& Mingxin, Y. (2007). Thermo-physical properties of epoxy nanocomposites reinforced with amino-functionalized multi-walled carbon nanotubes. Comp. A 38, 1331-1336. doi:10.1016/j.compositesa.2006.10.012.

21. Liu, J.Q., Xiao, T., Liao K. \& Wu, P. (2007). Interfacial design of carbon nanotube polymer composites: a hybrid system of noncovalent and covalent functionalizations. Nanotechnology 18(16), 165701. doi:10.1088/0957-4484/18/16/165701.

22. Zhou, Y., Pervin, F., Lewis, L. \& Jeelani, S. (2007). Experimental study on the thermal and mechanical properties of multi-walled carbon nanotube-reinforced epoxy. Mat. Sci. Eng. A 452, 657-664. doi:10.1016/j.msea. 2006.11.066

23. Gojny, F.H. \& Schulte, K. (2004). Functionalisation effect on the thermo-mechanical behaviour of multi-wall carbon nanotube/epoxy-composites. Compos. Sci. Tech. 64(15), 2303. doi:10.1016/j.compscitech.2004.01.024.

24. Hadjiev, V.G., Lagoudas, D.C., Oh, E.S., Thakre, P., Davis, D., Files, B.S., Yowell, L., Arepalli, S., Bahr, J.L. \& Tour, J.M. (2006). Buckling instabilities of octadecylamine functionalized carbon nanotubes embedded in epoxy. Compos. Sci. Tech. 66(1), 128-136. doi:10.1016/ j.compscitech.2005.01.004.

25. Martin, C.A., Sandler, J.K.W., Windle, A.H., Schwarz, M.K., Baunhofer, W., Schulte, K. \& Shaffer, M.S.P. (2005). Electric field-induced aligned multi-wall carbon nanotube networks in epoxy composites. Polymer 46(3), 877-886. doi:10.1016/j.polymer.2004.11.081.

26. Fidelus, J.D., Wiesel, E., Gojny, F.H., Schulte, K. \& Wagner H.D. (2005). Thermo-mechanical properties of randomly oriented carbon/epoxy nanocomposites. Comp. $A$ 36(11), 1555-1561. doi:10.1016/j.compositesa. 2005.02.006.

27. Gojny, F.H., Wichmann, M.H.G., Fiedler, B., Bauhofer, W. \& Schulte, K. (2005). Influence of nanomodification on the mechanical and electrical properties of conventional fibre-reinforced composites. Comp. A 36(11), 1525-1535. doi:10.1016/j.compositesa.2005. 02.007 .

28. Potschke, P., Fornes, T.D. \& Paul, D.R. (2002). Rheological behavior of multiwall carbon nanotubes/ polycarbonate composites. Polymer 43, 3247-55. doi:10.1016/S0032-3861(02)00151-9.

29. Mitchell, C.A., Bahr, J.L., Arepalli, S., Tour, J.M. \& Krishnamoorti, R. (2002). Dispersion of functionalized carbon nanotubes in polystyrene. Macromolecules 35, 8825-30. doi: 10.1021/ma020890y.

30. Kim, J.A., Seong, D.G., Kang, T.J. \& Youn, J.R. (2006). Effects of surface modification on rheological and mechanical properties of CNT/epoxy composites. Carbon 44(10), 1898-1905. doi:10.1016/j.carbon.2006.02.026.

31. Gojny, F.H., Nastalczyk, J., Rosłaniec, Z., Schulze, K. (2003). Surface modified multi-walled carbon nanotubes in CNT/epoxy-composites. Chem. Phys. Lett. 370, 820824. 